\title{
Adolescent Maturation of Dopamine D1 and D2 Receptor Function and Interactions in Rodents
}

\author{
Jennifer B. Dwyer*, Frances M. Leslie \\ Department of Pharmacology, University of California, Irvine, Irvine, California, United States of America \\ * Jennifer.dwyer@yale.edu
}

\section{fopenaccess}

Citation: Dwyer JB, Leslie FM (2016) Adolescent Maturation of Dopamine D1 and D2 Receptor Function and Interactions in Rodents. PLoS ONE 11 (1): e0146966. doi:10.1371/journal.pone.0146966

Editor: Cheryl M McCormick, Brock University, CANADA

Received: July 30, 2015

Accepted: December 23, 2015

Published: January 19, 2016

Copyright: @ 2016 Dwyer, Leslie. This is an open access article distributed under the terms of the Creative Commons Attribution License, which permits unrestricted use, distribution, and reproduction in any medium, provided the original author and source are credited.

Data Availability Statement: All relevant data are within the paper and its Supporting Information files.

Funding: This work was supported by (1) National Institute of Drug Abuse, Grant number DA19138, funding to FML. The funders had no role in study design, data collection and analysis, decision to publish, or preparation of the manuscript. (2) The PhRMA Foundation Paul Calabresi Medical Student Fellowship (http://www.phrmafoundation.org/2015awards/other-awards/clinical-pharmacology/paulcalabresi-medical-student-fellowship/) to JBD. The funders had no role in study design, data collection and analysis, decision to publish, or preparation of the manuscript.

\section{Abstract}

Adolescence is a developmental period characterized by heightened vulnerability to illicit drug use and the onset of neuropsychiatric disorders. These clinical phenomena likely share common neurobiological substrates, as mesocorticolimbic dopamine systems actively mature during this period. Whereas prior studies have examined age-dependent changes in dopamine receptor binding, there have been fewer functional analyses. The aim of the present study was therefore to determine whether the functional consequences of D1 and D2-like activation are age-dependent. Adolescent and adult rats were given direct D1 and D2 agonists, alone and in combination. Locomotor and stereotypic behaviors were measured, and brains were collected for analysis of mRNA expression for the immediate early genes (IEGs), cfos and arc. Adolescents showed enhanced D2-like receptor control of locomotor and repetitive behaviors, which transitioned to dominant D1-like mechanisms in adulthood. When low doses of agonists were co-administered, adults showed supra-additive behavioral responses to D1/D2 combinations, whereas adolescents did not, which may suggest age differences in D1/D2 synergy. D1/D2-stimulated IEG expression was particularly prominent in the bed nucleus of the stria terminalis (BNST). Given the BNST's function as an integrator of corticostriatal, hippocampal, and stress-related circuitry, and the importance of neural network dynamics in producing behavior, an exploratory functional network analysis of regional IEG expression was performed. This data-driven analysis demonstrated similar developmental trajectories as those described in humans and suggested that dopaminergic drugs alter forebrain coordinated gene expression age dependently. D1/ D2 recruitment of stress nuclei into functional networks was associated with low behavioral output in adolescents. Network analysis presents a novel tool to assess pharmacological action, and highlights critical developmental changes in functional neural circuitry. Immature D1/D2 interactions in adolescents may underlie their unique responses to drugs of abuse and vulnerability to psychopathology. These data highlight the need for age-specific pharmacotherapy design and clinical application in adolescence. 
Competing Interests: The authors have declared that no competing interests exist.

\section{Introduction}

Adolescence is a transitional developmental period between childhood and adulthood, during which drug abuse often begins [1], and psychopathologies emerge or change symptomology [2]. These unique clinical features are thought to be mediated by changes in the structural [3], functional [4], and neurochemical [5] organization of the brain. The dopamine (DA) system undergoes striking maturation during adolescence [6], which has significant implications for adolescent-onset drug abuse and psychiatric disorders. Consistent with developmental changes in DA signaling, adolescents respond uniquely to dopaminergic drugs. Teenagers exhibit blunted behavioral responses to indirect DA agonists like cocaine and amphetamine [7], but exaggerated responses to DA receptor antagonism [8].

Rodent adolescents (conservatively estimated at postnatal day (P) 28-42) are appropriate animal models, as they share evolutionarily conserved behaviors such as risk-taking, novelty seeking, and peer association, and display many of the same patterns of structural and neurochemical brain maturation as humans [9]. While the consensus definition of adolescence in the rodent continues to evolve in light of emerging behavioral, endocrine, and imaging data $[10,11]$, adolescent animals show unique responses to drugs that target the DA system, including blunted cocaine-induced locomotion [12], stereotypy [13], and sensitization [14]. Cocaine also induces unique patterns of neural activation in adolescents, as measured by immediate early gene (IEG) expression $[15,16]$ suggesting that the neural circuitry underlying behavioral responses is immature.

The effects of cocaine are predominantly mediated by the prolonged action of DA at D1-like and D2-like receptors. Although initially categorized by the ability to activate (D1-like) or inhibit (D2-like) adenylyl cyclase, these receptors have since been shown to couple to multiple signaling pathways [17]. D1 receptors not only couple to Gs proteins (D1[Gs]) to stimulate adenylyl cyclase, but also to $\mathrm{Gq}$ proteins $(\mathrm{D} 1[\mathrm{Gq}])$ which activate phospholipase $\mathrm{C}$ and intracellular $\mathrm{Ca}^{++}$release [18], and may have differential interactions with D2-like receptors [19]. While most D1-like agonists have some efficacy at D1[Gs] and D1[Gq], second messengerselective agonists have been developed [20]. Although few studies have assessed second-messenger selective signaling in adolescence [21], DA receptor expression is known to be agedependent, with transient overproduction and subsequent pruning of D1 and D2 binding sites in the adolescent prefrontal cortex [6,22] and striatum [23,24].

Although age differences in the functional consequences of receptor activation are less wellstudied, rodent behavioral and imaging studies suggest that adolescent D1 receptors are hypofunctional and D2 receptors are hyperfunctional $[25,26]$. However, it is the synergistic interaction of combined D1/D2 stimulation that is thought to mediate behavioral responses and corticostriatal IEG expression in adults [27,28], although significant controversy remains regarding whether molecular versus circuit level mechanisms are predominantly at play [29]. While there have been few dedicated evaluations of the ontogeny of this phenomenon [30,31], molecular evidence suggests that D1/D2 synergy is immature in adolescence [19], which could underlie blunted behavioral responses to indirect DA agonists. The present study uses behavioral, neurochemical, and functional network approaches to test the hypothesis that functional $\mathrm{D} 1 / \mathrm{D} 2$ interactions are immature during adolescence. The following data suggest that D1/D2 synergy may not be a fundamental feature of adolescent locomotor control and corticostriatial engagement as it is in adults. Adaptation of network analysis generates a further hypothesis that D1/D2-mediated recruitment of stress nuclei into functional networks inhibits locomotor activity in adolescence. 


\section{Materials and Methods}

\section{Materials}

Quinpirole hydrocloride (Tocris Bioscience, Ellisville, MO) was dissolved in sterile saline. SKF83959 (Sigma Aldrich, St. Louis, MO) and SKF83822 (NIMH Chemical Synthesis Program, Bethesda, MD) were initially dissolved in 10\% DMSO and diluted in sterile saline. For in situ hybridization, the following materials were used: poly-L-lysine, RNaseA, restriction enzymes, T3, T7 polymerases, proteinase K and yeast tRNA (Boehringer Mannheim Biochemicals, Indianapolis, IN); formamide (Fluka, Ronkonkoma, NY); dextran sulfate (Pharmacia, Piscataway, NJ); Hyperfilm, Bmax (Amersham, Arlington Heights, IL); ${ }^{35}$ S-Uridine triphosphate $\left({ }^{35} \mathrm{~S}-\mathrm{UTP}\right)$ (specific activity: 20-40 Ci/mmol) (Perkin Elmer).

\section{Animals}

Male Sprague-Dawley rats (Charles River, Wilmington, MA) were group housed in a temperature $\left(21^{\circ} \mathrm{C}\right)$ and humidity $(50 \%)$ controlled room on a $12 \mathrm{~h}$ light - dark cycle (lights on 07001900), with unlimited access to food and water. Adolescents, aged P32 on the experimental day, and adults, aged P90, were habituated to the vivarium and handled for 5 days before use. Each animal participated in one experiment, receiving a single drug and dose. Experiments were carried out in accordance with, and were explicitly approved by the Institutional Animal Care and Use Committee (IACUC) at the University of California, Irvine, and were consistent with federal guidelines.

\section{Behavior (Locomotion and Stereotypy)}

Experiment 1. To assess age differences in the behavioral sensitivity to D1 and D2-like agonists, dose response curves were constructed in adolescents and adults. Animals were assessed for locomotor and stereotypic behavior following the administration of the D1[Gs]selective agonist, SKF83822 [32], the D1[Gq]-selective agonist, SKF83959 [33], or the D2-like agonist, quinpirole [34] (see S1 File, Supplemental Methods).

Experiment 2. To examine D1/D2 interactions at the behavioral level, locomotion and stereotypy induced by low-dose combinations of quinpirole and either SKF83822 or SKF83959 were assessed. While arguably the most thorough way to assess drug interactions entails testing multiple D1/D2 combinations corresponding to several different points of efficacy along the dose response curves [35], conducting such a behavioral analysis at two age points would be difficult to power within ethical standards of animal use. Thus, the simplified approach of Johnstone et al.[36] was chosen as one way to evaluate D1/D2 interactions, by assessing combinations of low agonist doses (chosen based on the dose response curves from Experiment 1), which did not significantly increase locomotor behavior relative to saline on their own. The goal of these studies was to evaluate whether D1/D2 combinations at half-doses are able to produce behavior that additive doses of either agonist alone are unable to stimulate. Synergistic or supra-additive D1/D2 interactions were assessed by comparing D1/D2 combination doses with additive doses of each agonist alone, as described previously [36]. Adolescent and adult rats were randomly assigned to one of 6 treatment groups: saline, quinpirole $(0.4 \mathrm{mg} / \mathrm{kg})$, SKF83822 $(0.06 \mathrm{mg} / \mathrm{kg})$, SKF83959 $(0.6 \mathrm{mg} / \mathrm{kg})$, quinpirole $(0.2 \mathrm{mg} / \mathrm{kg})+\mathrm{SKF} 83822(0.03 \mathrm{mg} / \mathrm{kg})$, or quinpirole $(0.2 \mathrm{mg} / \mathrm{kg})+$ SKF83959 $(0.3 \mathrm{mg} / \mathrm{kg})$. Following behavioral testing (i.e. $30 \mathrm{~min}$ following drug injection, chosen as $c f o s$ and cytoplasmic arc mRNA expression peaks 30 minutes poststimulus $[37,38]$ ), animals were sacrificed via rapid decapitation, and brains were collected, frozen in $-20^{\circ} \mathrm{C}$ isopentane, and stored at $-80^{\circ} \mathrm{C}$ until use for in situ hybridization. 


\section{In Situ Hybridization}

Twenty $\mu \mathrm{m}$ coronal brain sections were cut and processed for $c$ fos and arc in situ hybridization and were analyzed quantitatively via computer-based image analysis (MCID, Image Research Inc., St Catharines, ON, Canada) [39] (see also S1 File, Supplemental Methods). Levels of mRNA expression were determined in a priori regions of interest, based on their expression of $\mathrm{D} 1$ and $\mathrm{D} 2$ receptors, their known roles in DA-mediated behaviors, and their expression of both cfos and arc: prefrontal cortex (cingulate (Cg1), prelimbic (PrL), infralimbic (IL), ventrolateral/orbital (VLO)); sensorimotor cortex (primary motor (M1), secondary motor (M2), primary sensory (S1), caudal primary motor (cM1), agranular insular (AI), caudal agranular insular (cAI)); striatum (dorsomedial caudate putamen $(\mathrm{dmCPu})$, dorsolateral caudate putamen $(\mathrm{dlCPu})$, ventromedial caudate putamen $(\mathrm{vmCPu})$, ventrolateral caudate putamen $(\mathrm{vlCPu})$ ), nucleus accumbens core (NAcC), nucleus accumbens shell (NAcSh)); hippocampus (CA1, CA2, CA3, dentate gyrus (DG), medial septum (MS), lateral septum (LS)); and amygdala/hypothalamus (bed nucleus of the stria terminalis (BNST), paraventricular nucleus of the hypothalamus (PVN), basolateral amygdala (BLA), central nucleus of the amygdala (CeA), medial nucleus of the amygdala (MeA)).

\section{Data Analysis}

Behavioral data. Locomotion and stereotypy were analyzed separately for each drug. Initial analyses of 30 min totals of drug-induced activity included 2-way ANOVA, with age and drug dose as dependent variables for dose-response data, and age and drug for combination data. Following a significant effect or interaction of age, adolescents and adults were analyzed separately via 1-way ANOVA, with Dunnett or Bonferonni post-hoc tests.

While there is some debate regarding the parametric analysis of stereotypic data [40], the scale used in the present study [41] has traditionally been analyzed parametrically. This scale largely measures intensity of behavior, rather than mere counting of instances of behavior (see S1 File, Supplemental Methods). Shapiro-Wilk testing of normality revealed that the majority of experimental groups conformed to the assumption of normality, and the ANOVA is a parametric test that is robust to even gross deviations in normality [42].

Immediate early gene regional analysis. Analysis of individual regional cfos and arc mRNA expression consisted of a 2-way ANOVA with age and drug as dependent variables. Following a significant effect of age, or an interaction of age with drug, adolescents and adults were analyzed separately via 1-way ANOVA for drug, using Bonferroni post-hoc corrections to compare all drug doses to each other. If there were no effects of age, adolescents and adults were pooled and analyzed via 1-way ANOVA for drug with Bonferroni post-hoc corrections. As with the behavioral data, IEG responses were considered synergistic if the D1/D2 combination was significantly different from both saline and from the additive doses of either agonist alone.

Analysis of cfos and arc coordinated gene expression. In order to assess network-level coordinated gene expression (CGE), we adapted functional network analysis approaches to regional IEG data [43] (see also S1 File, Supplemental Methods). An adjacency matrix was constructed for each gene ( $c f o s, \operatorname{arc}$ ), in each drug condition, for both adolescents and adults, yielding 24 matrices (S1 Fig provides an example). Each weighted, symmetrical matrix was composed of Pearson coefficients ( $r$ ) derived from the intersubject correlation of IEG expression between each pair of brain regions analyzed ( $27 \times 27$ regions). Matrices were then thresholded at $\mathrm{p}<0.05$, setting all non-significant $\mathrm{r}$-values to zero (S2 Fig provides an example). While the pros and cons of liberal versus conservative network thresholds continue to be debated [44], a rather stringent visualization threshold was selected in order to examine the 
most robust relationships across several drug conditions. Thresholded network matrices were imported into UCINET software and visualized using Netdraw (UCINET 6.0, Analytic Technologies, Lexington, $\mathrm{KY}$ ). Individual brain regions were displayed as network nodes and were presented in pseudoanatomical space (S3 Fig). The r-values denoting significant statistical associations between two regions (i.e. CGE, analogous to functional connectivity) were displayed as edges or links connecting two nodes. Both positive and negative functional relationships were visualized, with black lines denoting positive $r$-values and red lines denoting negative r-values.

Using the open-source brain connectivity toolbox of Sporns [43], community structure was determined by assessing modularity of each network (Matlab R2010a, MathWorks, Natick, MA). This function identifies nodes participating in highly interconnected subgroups within the larger network. The color outlining the nodes demonstrates those that belong to the same subcommunities, highlighting functional relationships between areas that may be anatomically distant.

D1/D2-activated adolescent and adult IEG networks were then compared with networks in saline-treated animals at each age. While thresholded matrices were used for visualization purposes, all $r$-values were included in network comparisons. Fischer r-to-z transformations were applied to improve normality. Drug-induced differences of correlation strength between each regional pair were calculated by dividing the difference between the $\mathrm{z}$ scores by the standard error of the difference. $\mathrm{P}$ values associated with $\mathrm{Z}$ difference scores were corrected using false discovery rate [45] $(q=0.35)$. A liberal threshold was chosen with the priority of minimizing Type II errors, which are exacerbated with conservative thresholds in networks with low signal-to-noise [46], while still providing moderate Type I error correction. Between-network differences were illustrated using UCINET and Netdraw software.

\section{Results}

\section{Age Differences in Behavioral Responses to D1 and D2-Like Agonists}

Significant age differences were observed in behavioral responses to D1 and D2-like agonists (Fig 1). As has been reported previously [25,34], quinpirole-induced locomotion decreased with age. Ambulation (Fig 1A) was influenced by drug dose $(\mathrm{F}(5,78)=7.653, \mathrm{p}<0.001)$, age ( $\mathrm{F}$ $(1,78)=39.226, \mathrm{p}<0.001)$, and the interaction of dose with age $(\mathrm{F}(5,78)=5.786, \mathrm{p}<0.001)$, with quinpirole increasing locomotion in adolescents $(\mathrm{F}(5,41)=7.631, \mathrm{p}<0.001)$, but not adults $(\mathrm{F}(5,37)=1.821, \mathrm{p}=0.133)$. Stereotypy (Fig $1 \mathrm{~B})$ was also influenced by drug dose ( $\mathrm{F}$ $(5,80)=55.367, \mathrm{p}<0.001)$, age $(\mathrm{F}(1,80)=11.192, \mathrm{p}=0.001)$, and the interaction of dose with age $(\mathrm{F}(5,80)=4.967, \mathrm{p}=0.001)$. While quinpirole increased stereotypy in both adolescents $(\mathrm{F}$ $(5,42)=28.087, \mathrm{p}<0.001)$ and adults $(\mathrm{F}(5,38)=33.392, \mathrm{p}<0.001)$, adolescents showed significantly greater stereotypy at several quinpirole doses, despite higher baseline stereotypy in adults.

In contrast, activity induced by the D1[Gs]-selective agonist, SKF83822, increased with age. Locomotion (Fig $1 C$ ) showed an effect of drug dose $(F(5,89)=6.811, \mathrm{p}<0.001)$ and a dose $\mathrm{x}$ age interaction $(\mathrm{F}(5,89)=2.957, \mathrm{p}=0.016)$. Although SKF83822 increased locomotion in both adolescents $(\mathrm{F}(5,41)=3.527, \mathrm{p}=0.010)$ and adults $(\mathrm{F}(5,48)=6.511, \mathrm{p}<0.001)$, adults showed significantly greater ambulatory activity at the $1 \mathrm{mg} / \mathrm{kg}$ dose. Age $(\mathrm{F}(1,91)=20.455, \mathrm{p}<0.001)$ and drug dose $(\mathrm{F}(5,91)=21.955, \mathrm{p}<0.001)$ also influenced stereotypy (Fig 1D). While there were drug effects in both adolescents $(F(5,42)=12.312, \mathrm{p}<0.001)$ and adults $(\mathrm{F}(5,49)=11.006$, $\mathrm{p}<0.001)$, stereotypy was significantly higher in adults.

The D1 [Gq]-selective agonist, SKF83959, induced low levels of ambulatory activity (Fig 1E), that were influenced by drug dose $(F(4,60)=3.541, \mathrm{p}=0.012)$, but not age $(\mathrm{F}(1,60)=1.233$, 
A Quinpirole (D2)-Induced Ambulatory

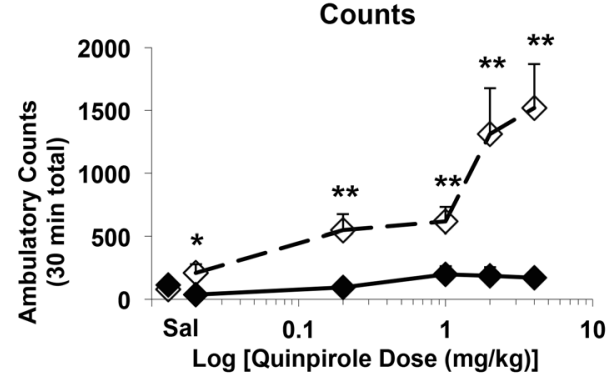

C SKF83822 (D1[Gs])-Induced Ambulatory

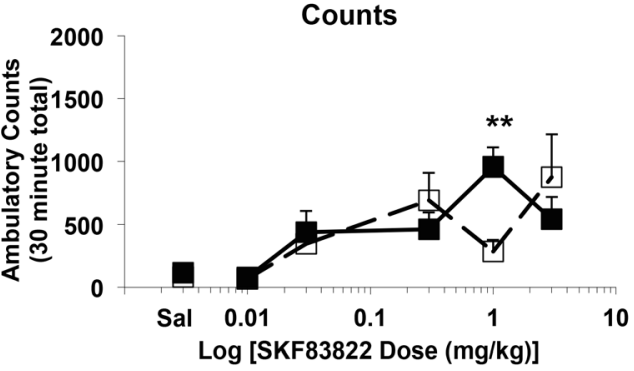

E SKF83959 (D1[Gq])-Induced Ambulatory

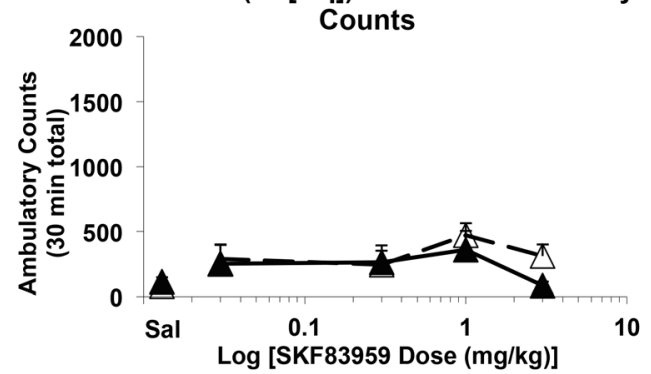

B Quinpirole (D2)-Induced Stereotypy

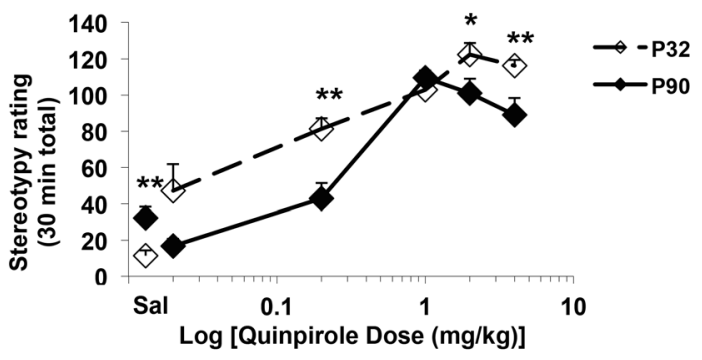

D SKF83822 (D1[Gs])-Induced Stereotypy

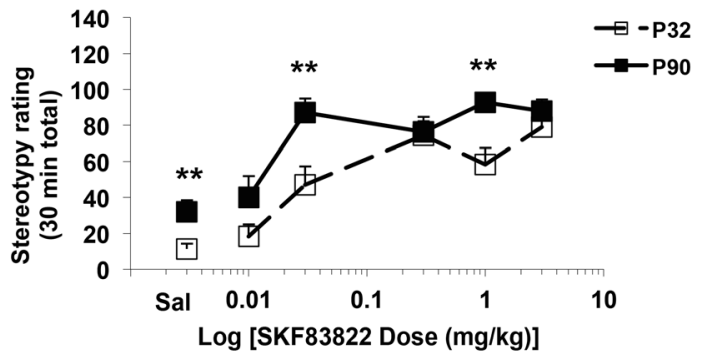

F SKF83959 (D1[Gq])-Induced Stereotypy

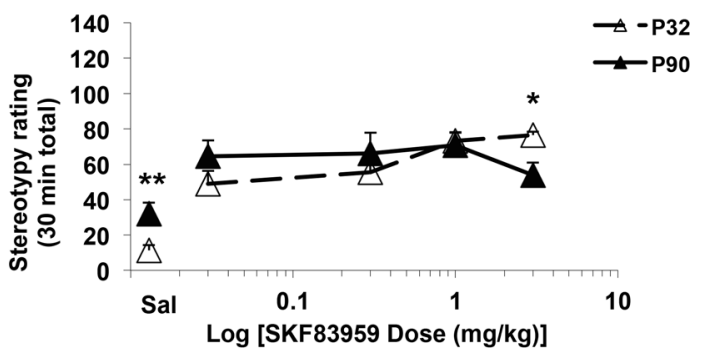

Fig 1. Dose Response Curves for Agonist-Induced Behavioral Response. The D2 agonist, quinpirole, stimulates greater locomotor (A) and stereotypic (B) behavior in adolescents (P32) than adults (P90). The selective D1[Gs] agonist, SKF83822, stimulates more locomotor (C) and stereotypic (D) behavior in adults than adolescents. While there are no significant age differences locomotor response to the selective D1[Gq] agonist, SKF83959 (E), 3.0mg/kg SKF83959 stimulates more stereotypy in adolescents than adults $(\mathbf{F})$. Significant age difference, ${ }^{*} p<0.05,{ }^{*} p<0.01 ; n=6-8$ per group.

doi:10.1371/journal.pone.0146966.g001

$\mathrm{p}=0.271)$. In contrast, there was a significant interaction of drug dose with age $(\mathrm{F}(4,59)=$ 3.147, $\mathrm{p}=0.021$ ) for SKF83959-induced stereotypy (Fig 1F). Although there were drug effects in both adolescents $(\mathrm{F}(4,29)=29.708, \mathrm{p}<0.001)$ and adults $(\mathrm{F}(4,30)=4.406, \mathrm{p}=0.006)$, adolescents exhibited higher SKF83959-induced stereotypy at the highest dose tested $(\mathrm{p}=0.027)$.

\section{Age Differences in Behavioral Responses to D1/D2 Agonist Combinations}

Behavioral interactions between D1 and D2 receptors were age-dependent, with D1/D2 agonist combinations producing supra-additive responses in adults but not adolescents (Fig 2). Ambulatory response to D1/D2 combinations (Fig $2 \mathrm{~A}$ ) was influenced by drug $(\mathrm{F}(5,167)=4.863$, $\mathrm{p}<0.001)$ and the interaction of drug with age $(\mathrm{F}(5,167)=2.659, \mathrm{p}=0.024)$. There was a strong trend towards a drug effect on adolescent locomotion $(F(5,67)=2.298, p=0.055)$, primarily driven by quinpirole, the only treatment significantly different from saline $(p=0.031)$. Adult locomotion was influenced strongly by drug treatment $(F(5,100)=8.072, p<0.001)$, with the 
A D1/D2 Agonist- Induced Ambulatory Counts

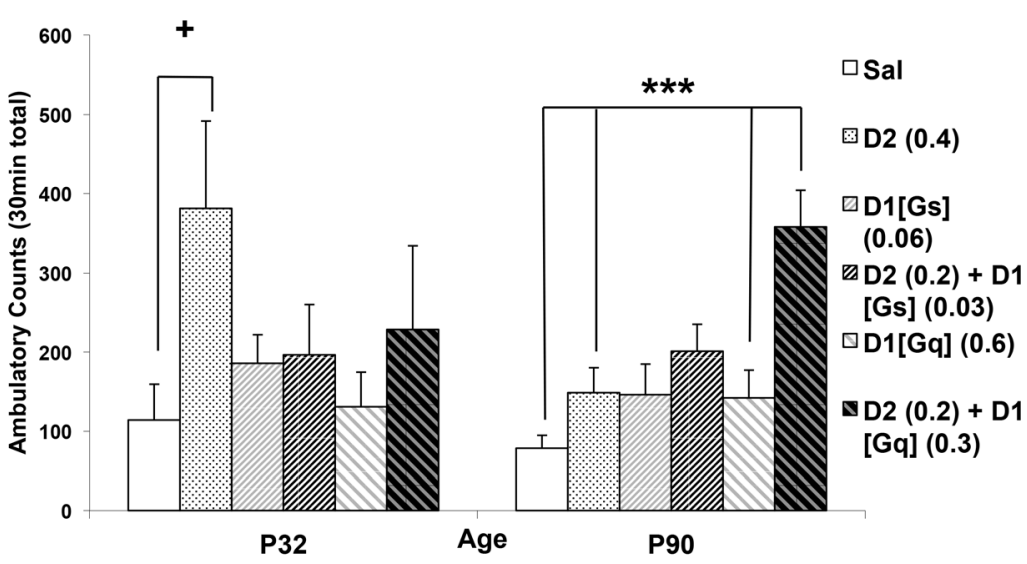

B D1/D2 Agonist- Induced Stereotypy

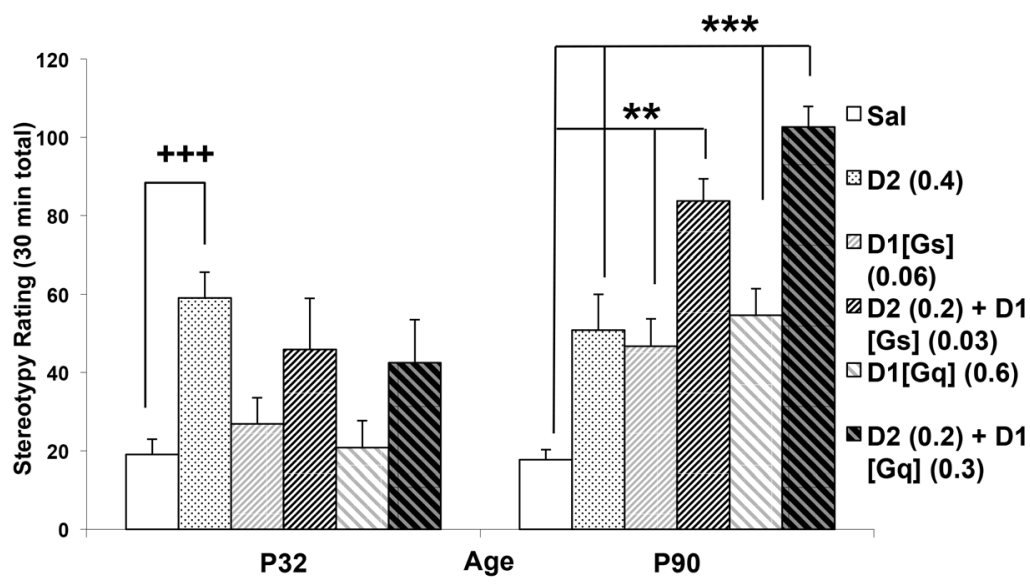

Fig 2. Age Differences in Behavioral Synergy. (A) Locomotor and stereotypic response to quinpirole and SKF83822, alone and in combination (D2 (0.2) + D1[Gs]). (B) Locomotor and stereotypic response to quinpirole and SKF83959, alone and in combination (D2 (0.2) + D1[Gq]). ** ${ }^{*}<0.001$ vs. saline and additive doses of each agonist along at the same age. $+p<0.05$ vs. saline, $++p<0.01 ; n=10-19$ per group

doi:10.1371/journal.pone.0146966.g002

response to the combination of SKF83959+quinpirole (D1[Gq]/D2) being significantly greater than that of animals treated with saline $(\mathrm{p}<0.001)$, quinpirole $(\mathrm{p}<0.001)$ and SKF83959 $(\mathrm{p}<0.001)$ alone, suggesting a supra-additive drug interaction. In contrast, the response to a combination of SKF83822+quinpirole (D1[Gs]/D2) was not significantly different from additive doses of either agonist alone.

Stereotypy (Fig 2B) following combined agonist treatment also showed effects of age ( $\mathrm{F}$ $(1,171)=33.238, \mathrm{p}<0.001)$, drug $(\mathrm{F}(5,171)=18.668, \mathrm{p}<0.001)$, and an interaction of age with drug $(\mathrm{F}(5,171)=7.258, \mathrm{p}<0.001)$. As with locomotion, adolescent stereotypy was influenced by drug $(\mathrm{F}(5,69)=5.438, \mathrm{p}<0.001)$, but only quinpirole increased stereotypy relative to saline $(\mathrm{p}<0.001)$. Adult stereotypy was also significantly influenced by drug $(\mathrm{F}(5,102)=23.321$, $\mathrm{p}<0.001)$. In adults, however, the combination of SKF83959+quinpirole (D1[Gq]/D2) increased stereotypy relative to saline $(\mathrm{p}<0.001)$, SKF83959 $(\mathrm{p}<0.001)$, and quinpirole alone $(\mathrm{p}<0.001)$, suggesting a supra-additive potentiation. Similarly, the stereotypic response to the combination of SKF83822+quinpirole (D1[Gs]/D2) was significantly higher than that of saline 
$(\mathrm{p}<0.001)$, SKF83822 $(\mathrm{p}=0.001)$, or quinpirole $(\mathrm{p}=0.005)$ alone, suggesting supra-additive $\mathrm{D} 1[\mathrm{Gs}] / \mathrm{D} 2$ interactions.

\section{Regional IEG Expression}

Given the considerable age differences in locomotor responses to D1/D2 agonists, both activity (cfos) and plasticity-related (arc) gene expression was assessed in behaviorally tested animals (S1 and S2 Tables). The most robust regional drug and age effects were observed in nuclei of the extended amygdala and stress system, particularly the BNST (Fig 3). BNST cfos expression was sensitive to age $(\mathrm{F}(1,61)=5.089, \mathrm{p}=0.028)$, with greater BNST cfos expression in adults compared to adolescents. There was not a significant age $\mathrm{x}$ drug interaction $(\mathrm{F}(5,61)=0.280$, $\mathrm{P}=0.923)$, and both ages showed similar robust drug effects (adolescents $(\mathrm{F}(5,31)=7.415$, $\mathrm{p}<0.001)$; adults $(\mathrm{F}(5,30)=9.363, \mathrm{p}<0.001)$ ). At both ages, D2 agonism alone (adolescent $\mathrm{p}=0.024$; adult $\mathrm{p}=0.003$ ) and in combination with both $\mathrm{D} 1[\mathrm{Gs}]$ (adolescent $\mathrm{p}=0.08$, adult $\mathrm{p}=0.001$ ) and $\mathrm{D} 1[\mathrm{Gq}]$ agonists (adolescent $\mathrm{p}=0.002$, adult $\mathrm{p}=0.010$ ) increased $c f o s$ expression relative to saline controls. BNST arc expression was sensitive to both drug $(\mathrm{F}(5,59)=$ 14.187, $\mathrm{p}<0.001)$ and the interaction of drug with age $(\mathrm{F}(5,59)=2.958, \mathrm{p}=0.019)$. Although agonists increased arc expression in both adolescents $(\mathrm{F}(5,29)=11.863, \mathrm{p}<0.001)$ and adults $(\mathrm{F}(5,30)=6.280, \mathrm{p}<0.001)$, supra-additive $\mathrm{D} 1 / \mathrm{D} 2$ interactions were observed in adolescents only. The BNST serves as an integration point linking cortical, hippocampal, and striatal circuitry to the extended amygdala and stress-sensitive nuclei [47]. It receives a multitude of anatomically and neurochemically distinct afferents, and has similar efferent heterogeneity [48], making it a densely complex nucleus whose influences at the circuit level can be difficult to predict, at times producing divergent responses depending on which subpopulations of neurons are activated [49]. Thus, activation measured at the resolution of in situ hybridization cannot be assumed to reflect identical influences on behaviorally relevant neural networks. Given the complex integrative role of the BNST and the importance of network dynamics in producing behavioral output [50], we undertook a data-driven exploratory assessment of coordinated neural activity via adaptation of functional network analysis to IEG data to examine the effects of dopaminergic stimulation on functional networks in adolescents and adults.

\section{Age Differences in Baseline CGE Networks}

To examine age differences in functional network architecture, regional networks of $c f o s$ and arc mRNA expression in saline-treated animals were constructed (Fig 4). Control cfos CGE maps exhibited marked organizational differences between adolescents and adults, with agedependent community structure (colors outlining nodes denote communities). Saline-treated adolescents (Fig 4A) had a greater overall number of functional relationships than adults (Fig $4 \mathrm{~B})$, congruent with human imaging studies suggesting that functional connectivity becomes less diffuse and more efficient in adulthood [51]. Although both adolescents and adults show intrastriatal cfos CGE in baseline conditions, extrastriatal functional relationships are agespecific.

Arc network interactions were distinct from those of $c f o s$, but shared some features of developmental transitions. Adolescents (Fig 4C) showed more coordinated arc expression both within brain areas (cortex, hippocampus, striatum), and across brain regions, which may reflect enhanced synchronized functional network plasticity in the developing brain. As with cfos, arc expression in the cortex was highly coordinated in adolescents, transitioning to more distributed cortical functional relationships in the adult (Fig 4D). Similarly, more functional relationships in arc networks were lost than gained in the transition from adolescence to adulthood. 

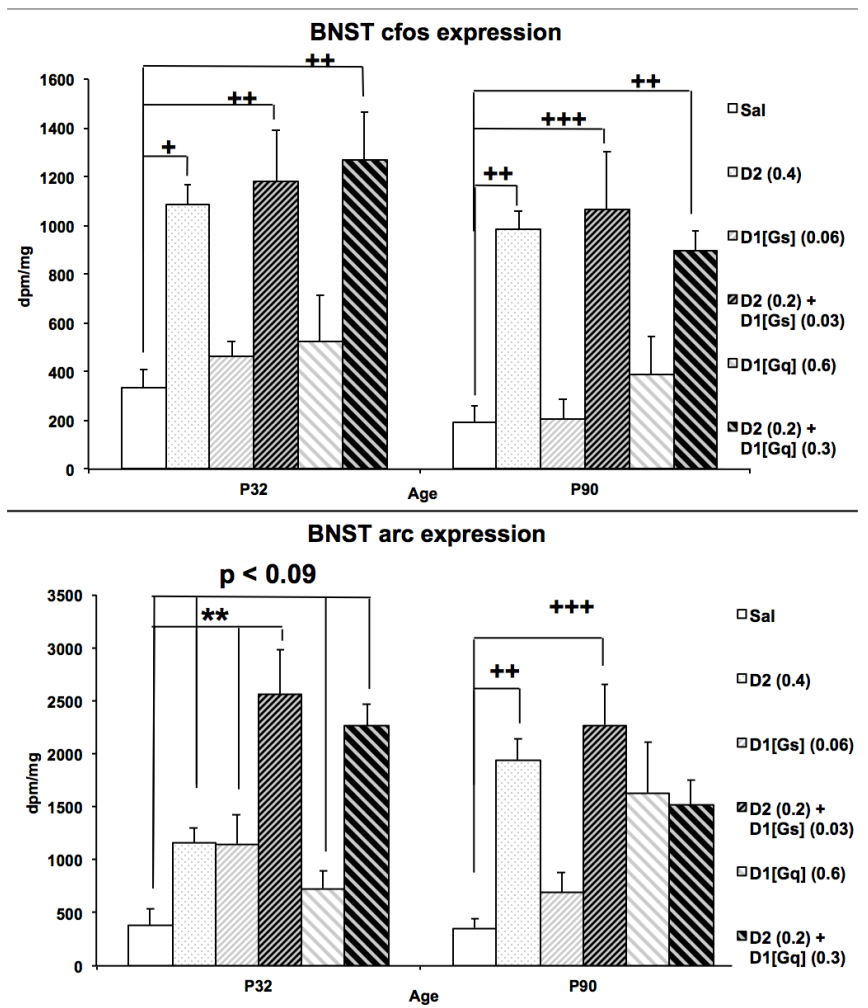

Fig 3. Age Differences in BNST IEG Synergy. (A) Cfos expression in the BNST of animals treated with saline, agonist alone, or in combination (B) Arc expression in the BNST of animals treated with saline, agonist alone, or in combination ${ }^{* *} p<0.001 \mathrm{vs}$. saline and additive doses of each agonist along at the same age. $+p<0.05$ vs. saline, $++p<0.01 ; n=6-7$ per group

doi:10.1371/journal.pone.0146966.g003

An exception, however, was coordinated arc mRNA expression between BLA and cortex, which matured post-adolescence.

\section{Age Differences in D1/D2 Agonist-Mediated CGE Networks}

Cfos. Drug-induced changes in CGE were assessed by comparing drug-activated networks to baseline networks at each age. Adolescents treated with quinpirole, who showed robust locomotor activity, had enhanced septostriatal CGE and loss of positive CGE within the stress system (BNST, MeA) (Fig 5A). D1[Gs]/D2-treated adolescents showed little locomotor behavior, but had the most extensive network-level enhancements, with increased cfos CGE within the cortex, between sensorimotor cortex and striatum, between amygdala/hypothalamus and the hippocampus, and between the hippocampus and striatum (Fig 5C). There was also loss of negative interactions between the MS/LS and striatal nuclei. Changes in adolescent $c f o s$ network activity resulting from $\mathrm{D} 1[\mathrm{Gq}] / \mathrm{D} 2$ treatment (Fig $5 \mathrm{E}$ ) were a small subset of those induced by $\mathrm{D} 1[\mathrm{Gs}] / \mathrm{D} 2$, and were focused on increased CGE between hippocampus and hypothalamus (PVN) and amygdala (CeA, BLA). In contrast, adult animals showed a loss of hippocampal network interactions following D2 agonist treatment, which was not evident with either D1/D2 combination. In adults, corticostriatal relationships were increased by D2 alone (Fig 5B) and the D1[Gq]/D2 combination (Fig 5F). Despite shared corticostriatal enhancement, the PVN was selectively integrated into networks of quinpirole-treated adults, who showed low levels of horizontal activity. Taken together, cfos CGE networks illustrated age differences in D1/D2 
P32
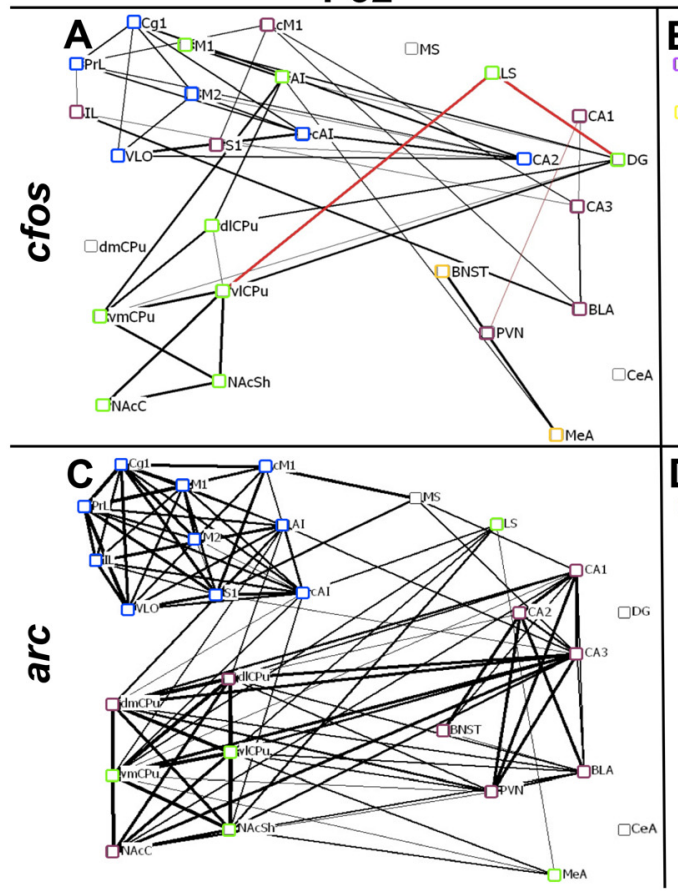

P90
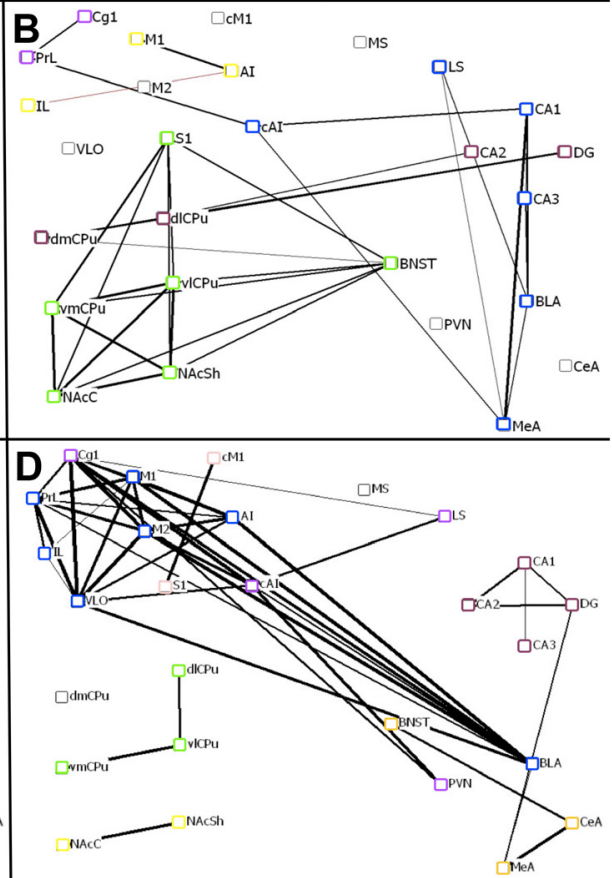

Fig 4. Baseline Cfos and Arc Networks. Nodes represent brain regions and are presented in pseudoanatomical space. Edges are lines connecting two nodes, and represent significant $r$ values $(p<0.05$, $n=6-7$ ), in which thicker lines correspond to more robust $r$ values. Positive and negative $r$ values are depicted with black and red lines, respectively. Colors outlining nodes denote modularity, in which nodes that share the same border color participate in the same sub-community. (A) Cfos networks in saline-injected adolescent controls exhibit local coordinated gene expression (CGE) in the cortex and striatum. (B) Adult baseline cfos networks are sparser than adolescent networks, and functional communities are comprised of more anatomically distributed nuclei. (C) Adolescent baseline arc networks are characterized by functional communities predominately comprised of nuclei that are anatomically proximal to each other, particularly in the cortex. (D) Adult baseline arc networks show a smaller number of functional interrelationships than adolescent networks, but demonstrate unique corticoaccumbens CGE.

doi:10.1371/journal.pone.0146966.g004

regulation of network architecture, with dopaminergic regulation of hippocampal interrelationships in adolescence and enhancement of corticostriatal relationships in adults. Drug treatments producing low behavioral output were associated with incorporation of stress nuclei into cfos CGE networks at both ages.

Arc. Network analysis of arc expression in animals treated with D1/D2 agonist combinations revealed both age-dependent and second-messenger selective modulation of plasticityrelated CGE (Fig 6). Despite robust effects of D1[Gs]/D2 treatment on adolescent $c f o s$ CGE, this drug combination did not significantly alter adolescent arc networks (Fig 6C). D1[Gq]/D2 treatment, in contrast, markedly disrupted the positively coordinated cortical arc expression seen in adolescent controls and introduced some negative interrelationships (Fig 5E). In adults, dopaminergic regulation of $\operatorname{arc}$ networks was also second-messenger specific. D1[Gs]/D2 treatment increased arc CGE within the cortex and between LS and striatal regions (Fig 5D). D1 $[\mathrm{Gs}] / \mathrm{D} 2$ also disrupted the highly correlated arc expression between BLA and cortex seen in adult controls (Fig 5D), as seen with D2 alone (Fig 5B), and induced a negative functional relationship between the CeA and hippocampus. In contrast, D1[Gq]/D2 treatment significantly increased corticostriatal, intracortical, and intrastriatal arc CGE (Fig 5F), without any effect on the tightly correlated BLA-cortex functional relationship. Taken together, dopaminergic 


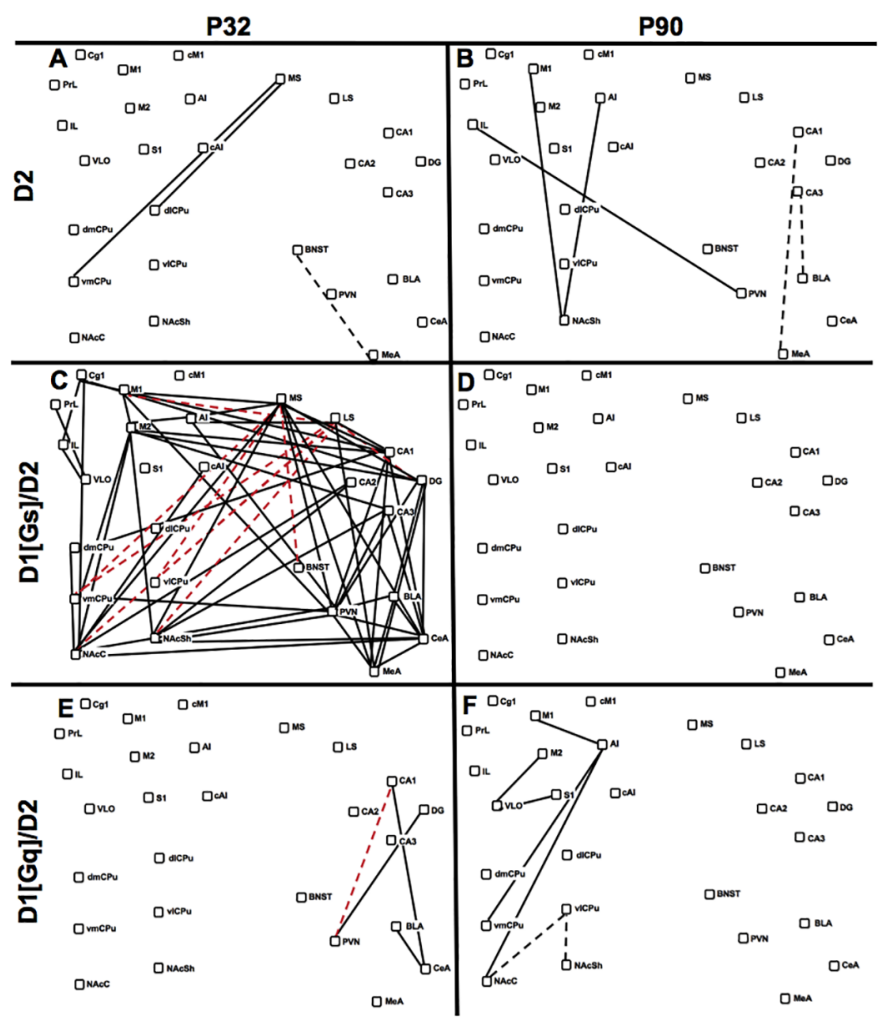

Fig 5. D1/D2-Induced Cfos Network Changes. Difference maps visually represent significant differences between baseline networks in saline-injected controls and that in animals injected with D1/D2 drug combinations. Nodes represent brain regions and are presented in pseudoanatomical space. Lines indicate functional relationships between nodes that are significantly altered by D1/D2 treatment relative to controls $(p<0.01, n=6-7)$. Solid black lines indicate gain of a positive cfos CGE. Dashed black lines indicate loss of positive cfos CGE. Solid red lines indicate gain of negative cfos CGE. Dashed red lines indicate loss of negative CGE. (A) Effects of D2 stimulation in adolescents. (B) Effects of D2 stimulation in adults. (C) D1[Gs]/ D2 combination treatment in adolescents. (D) Effects of D1[Gs]/D2 combination treatment in adults. (E) Effects of D1[Gq]/D2 combination treatment in adolescents. (F) Effects of D1[Gq]/D2 combination treatment in adults.

doi:10.1371/journal.pone.0146966.g005

modulation of adult arc CGE was highly second-messenger dependent with negative amygdalocortical regulation by $\mathrm{D} 2$ and D1[Gs]/D2 and positive corticostriatal regulation by D1[Gq]/ D2. In contrast, adolescents showed minimal impact of D2 and D1[Gs]/D2 stimulation on arc networks, but significant reduction of intracortical $\operatorname{arc}$ CGE by D1[Gq]/D2.

\section{Discussion}

These data demonstrate that the functional consequences of D1 and D2 receptor activation are immature during adolescence, and that D1[Gs] and D1[Gq] receptor interactions with D2 receptors are unique in both adolescents and adults. Behaviorally, quinpirole was more efficacious in adolescence, but its interactions with D1 agonists did not demonstrate the supra-additive D1/D2 interactions shown in adults, potentially underlying the blunted behavioral responses to indirect agonists that have been reported $[12,13]$. In contrast, the D1[Gs] agonist, SKF83822, was more effective in adults and interacted supra-additively with quinpirole to potentiate stereotypy, which may suggest synergistic interactions. The D1[Gq] agonist, SKF83959, induced little to no behavior alone, but robustly potentiated behavior when combined with quinpirole to induce locomotion and stereotypy in adults, consistent with prior 


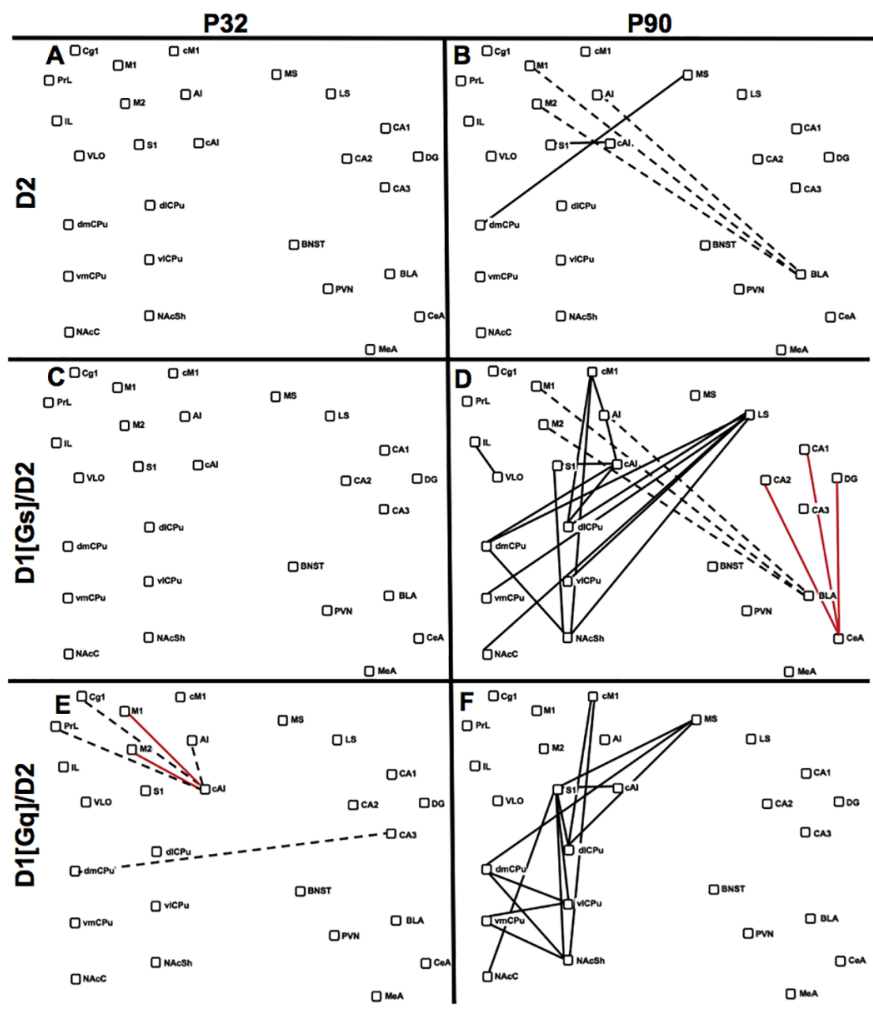

Fig 6. D1/D2-Induced Arc Network Changes. Difference maps visually represent significant differences between baseline networks in saline-injected controls and that in animals injected with D1/D2 drug combinations. Nodes represent brain regions and are presented in pseudoanatomical space. Lines indicate functional relationships between nodes that are significantly altered by D1/D2 treatment relative to controls $(p<0.01, n=6-7)$. Solid black lines indicate gain of a positive arc CGE. Dashed black lines indicate loss of positive arc CGE. Solid red lines indicate gain of negative arc CGE. Dashed red lines indicate loss of negative CGE. (A) Effects of D2 stimulation in adolescents. (B) Effects of D2 stimulation in adults. (C) D1[Gs]/D2 combination treatment in adolescents. (D) Effects of D1[Gs]/D2 combination treatment in adults. (E) Effects of D1[Gq]/D2 combination treatment in adolescents. (F) Effects of D1[Gq]/D2 combination treatment in adults.

doi:10.1371/journal.pone.0146966.g006

descriptions of D1/D2 behavioral synergy [41,52-54]. Several of these treatments robustly activated $c f o s$ and arc expression in the BNST, whose integrative function prompted an exploratory network-level analysis of CGE. Age differences in CGE networks in the drug-free state paralleled that of functional connectivity in human imaging studies [4], progressing from local and diffuse adolescent networks to distributed and efficient adult networks. CGE patterns also illustrated age- and second messenger-specific D1/D2 regulation of network architecture.

\section{Immature Behavioral D1/D2 Interactions During Adolescence}

Our data confirm prior findings that quinpirole is more efficacious in stimulating locomotion and stereotypy in adolescents than adults $[25,26]$. While quinpirole is non-selective within the D2-like family, quinpirole-stimulated locomotion in adolescence is sensitive to the D2 selective antagonist L-741,626, but not to a D3 or D4 selective antagonist [55]. Despite prior suggestions that D1 receptors are functionally underdeveloped in adolescence [26], this is the first report using second messenger selective agonists to confirm that D1[Gs]-linked stimulation induces greater behavioral response in adults. These findings suggest a developmental shift in DA regulation of ambulatory behavior from predominant control by $\mathrm{D} 2$ receptors in adolescence to D1 
[Gs] receptors in adults. While there are no available pharmacokinetic data comparing adolescent and adult metabolism of these experimental compounds, each drug significantly increased stereotypy at both ages (Fig 1) with similar timecourses (S4 Fig), suggesting significant CNS penetration. While subtle age differences in pharmacokinetic profiles cannot be excluded, significant pharmacodynamic age differences between adolescents and adults are supported by age differences in receptor expression [56], as well as age-specific effects of D1/D2 activation on neural circuit physiology [57], locomotor behaviors (Fig 2), and functional networks (Figs 5 and 6).

In adults, combined D1[Gs]/D2 stimulation supra-additively increased stereotypy, but not locomotion, whereas D1[Gq]/D2 supra-additively increased both behaviors. Thus, while D1 [Gq] activation alone fails to stimulate locomotor responses, it may more readily potentiate behavior when combined with D2 agonism, consistent with predictions from molecular studies [19]. In contrast, adolescents show a fundamental difference in D1/D2 interactions, lacking supra-additive potentiation of locomotion and stereotypy following both D1[Gs]/D2 or D1 $[\mathrm{Gq}] / \mathrm{D} 2$ treatment when tested at these low dose combinations. Since powering an ideal synergism study using multiple D1/D2 drug combinations at differing points of efficacy to conduct isobolgraphic statistical analysis [35] would be challenging, a simplified approach to examining D1/D2 interactions was taken here [36]. This approach aims to demonstrate positive functional interactions by showing that combinations of half-doses of ineffective agonist concentrations (i.e. those ineffective at stimulating locomotor behavior based on Experiment 1) produce a significant response when additive doses alone do not. The interpretation of these supra-additive interactions as synergistic is most straightforward for adult D1[Gq]/D2-stimulated locomotion, where neither agonist alone generates ambulation at any dose tested (Fig $1 \mathrm{~A}$ and 1E), but significant behavior is produced from the combination, similar to prior descriptions of requisite behavioral D1/D2 synergy [41,52-54]. For adult stereotypy, in which all agonists can produce significant behavior alone, isobolographic analysis would be needed to statistically confirm these interactions as synergistic. The interpretation is further complicated in adolescents, who not only fail to show the supra-additive effects assessed in this paradigm, but rather appear to exhibit negative functional interactions. The between-group experimental design and testing of only single D1/D2 combinations limits the statistical analysis of negative functional interactions, however antagonistic D1/D2 interactions in younger animals have been reported previously [30,31]. Future studies utilizing multiple direct agonist combinations to allow isobolographic statistical analysis of D1/D2 interactions are needed [35] to fully demonstrate the antagonistic and synergistic interactions that have been suggested in adolescents and adults, respectively. It has been reported that D1 and D2 receptors cannot be co-immunoprecipitated in the striatum of young animals, suggesting that the proposed, and somewhat controversial, $\mathrm{D} 1[\mathrm{Gq}] / \mathrm{D} 2$ heterooligomer is late maturing [19]. This lack of signalplex formation may provide a mechanism for the lack of supra-additive behavioral D1[Gq]/D2 interactions in adolescence, but does not readily provide an explanation for the negative interactions, suggesting that circuit-level mechanisms may be at play. Furthermore, although D1[Gs] receptors are thought to signal more traditionally in the striatum and not form functional signaling complexes with D2 receptors [19], we demonstrate significant behavioral interactions between D1[Gs] and D2 agonists in adults. Thus, some of the behavioral interactions between D1 and D2 agonists that we have observed likely reflect interaction at a circuit or network level rather than the molecular level.

To begin to assess the neural circuitry underlying these behaviors, saline and drug-stimulated $c f o s$ and arc expression was examined. As this behavioral paradigm focused on low-dose agonist interactions, low regional drug-induced IEG expression was expected, a limitation of the current design. Further studies using higher dose D1/D2 combinations are needed to 
demonstrate the ontogeny of regional corticostriatal IEG expression, as we have previously described for the indirect agonist cocaine [15]. While low-dose agonist-induced corticostriatal IEG was minimal, robust regional drug effects were demonstrated within stress-sensitive nuclei. The BNST, which functions to integrate corticostriatal circuitry with hippocampal, amygdala, and stress networks [47] is activated by psychostimulants [58] and by combined direct D1/D2 stimulation (Fig 3). While both ages showed activation of this nucleus following $\mathrm{D} 1 / \mathrm{D} 2$ stimulation, there were supra-additive D1/D2 interactions only in adolescents. This significant activation of the BNST by D1/D2 drug combinations in adolescence may contribute to the inhibited locomotor response seen at this age, as this nucleus is implicated in freezing behavior [59]. However, activation of the BNST in behaviorally tested animals was not associated with decreased behavioral output in all groups, and the cytoarchitectural diversity within this small nucleus makes it difficult to ascertain whether similar neuronal subpopulations are engaged across groups. Additionally, D1 and D2 receptor expression within this complex architecture is similarly complicated, and may be translationally regulated by stimuli like stress and dopamine release [60], making it difficult to predict the impacts that receptor stimulation may have at the circuit and behavioral levels. Since the BNST is well-positioned to influence network behavior and subtle differences in subregional activation can produce widely varying circuit dynamics [49], exploratory network analysis was undertaken to determine whether the observed behavioral synergistic and antagonistic interactions were associated with unique patterns of functional connectivity between brain regions.

\section{Correlated Interregional IEG Expression Is Influenced by Age and Drug}

Graph theoretical methods have been used to characterize and quantitate features of complex networks, and have been applied to both structural and functional systems in the brain [44]. Fundamental to this analysis is the assumption that brain regions comprising functional processing networks will have highly correlated neuronal activities [61] and, thus, functional connectivity reflects patterns of deviations from statistical independence between brain regions [62]. As there are diverse methodologies to measure regional brain activation, analysis of functional brain networks has been applied to numerous human imaging paradigms (fMRI [63], magnetoencephalography [64], electroencephalography [65] and PET [66]). There have been far fewer studies examining functional connectivity in animals, although a recent study using rodent fMRI suggests that resting networks in the rat share similar properties to those in humans [67].

Neuronal activation in rodents has been measured using IEG expression, particularly cfos activation, for many years $[68,69]$ and autoradiography provides exquisite spatial resolution compared to fMRI. Thus, functional network approaches are readily suitable to analyze IEG data in rodents. An additional benefit of applying network approaches to IEG analysis is that genes with functions related to plasticity can highlight networks of nuclei that may undergo coordinated synaptic modification. Whether drug exposure during adolescence alters developmental plasticity-related gene programs is a particularly important clinical question. Thus, we analyzed CGE of cfos mRNA as a high-resolution readout of functional associations in metabolic activity $[68,69]$ and CGE of arc mRNA to illustrate plasticity-related functional networks [70,71].

The present study is one of the first to adapt these network methods to examine CGE of $c f o s$ and $\operatorname{arc}$ mRNA expression and to examine developmental changes. As with resting human functional connectivity networks $[4,72,73]$, networks of $c f o s$ expression in rodent forebrain transitioned from local, diffuse adolescent CGE to distributed, efficient adult networks. Adolescent brain also exhibited strong arc CGE both within and between brain areas. Given the 
development of long-range structural [74] and functional relationships [73] in the transition to adulthood, high arc CGE is consistent with enhanced plasticity in the adolescent brain. While adults showed reduced overall arc CGE, coordination between the BLA and cortical nuclei was uniquely present in adulthood, potentially mediated by the late-maturing anatomical connection [74].

Complex, age-specific effects of D1/D2 agonists on CGE were observed. Although network comparisons in the present study are limited by power, group differences were observed even when using moderate correction by false discovery rate. Appropriate analysis to balance mitigation of Type I errors from multiple comparisons while avoiding the Type II errors inherent with conservative thresholds, particularly in low signal-to-noise networks, is an area of active debate [46]. The present study places an emphasis on avoiding Type II errors in this datadriven analytic approach. Testing of the hypotheses generated from these network studies with more conservative thresholding is currently underway.

While adolescent locomotor responses to combined D1/D2 stimulation were low, cfos CGE was substantially altered, particularly hippocampal relationships with hypothalamus and amygdala. Whereas adolescents treated with quinpirole alone showed only increased septostriatal cfos CGE and decreased CGE within the extended amygdala (Fig 5A), combination with either D1 agonist recruited stress nuclei to functional networks and was associated with low locomotor and stereotypic behavior. The hypothesis that adolescent locomotor behavior may be inhibited by D1/D2 activation of stress networks requires further testing. Adolescent arc networks were disrupted by DA agonists, with the D1[Gq]/D2 combination inducing striking dysregulation of cortical arc CGE. The impact of network disruption from acute or repeated adolescent drug exposure is not known, and future studies should address how these modifications occur over time using complementary longitudinal imaging approaches (e.g. fMRI) guided by predictions from high-resolution plasticity-related gene network analyses.

D1 and D2 agonists also modulated adult functional networks, with positive regulation of cfos CGE in corticostriatal circuitry that has been traditionally associated with DA-mediated behaviors [75]. Whereas quinpirole enhanced corticostriatal cfos CGE, it also recruited stress components into its network (Fig 5B). While adult D1/D2 activated networks showed second messenger specificity, neither treatment recruited components of the extended amygdala or stress system (Fig 5). Thus, as with adolescents, recruitment of stress circuitry into adult functional networks was associated with reduced locomotion. Plasticity-related networks also exhibited age-specific DA regulation, with arc CGE in the late-maturing BLA-cortex showing second-messenger specificity. While tightly correlated in control animals, BLA-cortical arc CGE was disrupted by quinpirole, alone and in combination with D1[Gs], but not with D1 [Gq]. In contrast, D1[Gq]/D2 increased arc CGE not only within the striatum, but also in corticostriatal and hippocampo-striatal circuitry. Thus, D1[Gq]/D2 induced the most robust behavioral synergy in adults, and showed unique enhancement of corticostriatal functional relationships, both at the level of immediate activation ( $c f o s)$ and of plasticity-related gene expression (arc). It is noteworthy that adolescents treated repeatedly with indirect agonists do not exhibit locomotor sensitization [14,76] (although see [12,77]), which relies on plasticity of corticostriatal circuits $[75,78]$. Thus, enhancement of corticostriatal coordinated plasticityrelated gene expression by $\mathrm{D} 1[\mathrm{Gq}] / \mathrm{D} 2$, but not $\mathrm{D} 1[\mathrm{Gs}] / \mathrm{D} 2$, may be predicted to induce locomotor sensitization. Although this hypothesis has not yet been tested explicitly, recent molecular studies provide support, showing that D1[Gq]/D2 but not D1[Gs]/D2 stimulation induces striatal BDNF expression [79], a critical step in the development of behavioral sensitization [80].

While these data suggest marked differences between adolescent and adult animals, they do not necessarily imply linear development of DA-mediated behaviors and modulation of 
functional networks. Indeed, some data suggest that juvenile animals resemble adults in several aspects of brain and behavior, with adolescents presenting as distinct from both younger and older animals [9]. The way in which adolescence is defined as a developmental period continues to evolve, undergoing refinement or expansion as new developmental data is acquired $[10,11]$. The animals in this study were tested prior to puberty, in what is generally considered early adolescence [9]. Thus, as the present study does not fully describe the ontogeny of these behavioral and network phenomena, future studies should incorporate a wider range of ages including early, mid, and late adolescence in order to thoroughly characterize the developmental trajectory. Another limitation of the present study is that the stress of animal shipment may have differential effects on animals transported at younger ages versus in adulthood. Early life stress impacts the development of a number of critical brain circuits, including the dopamine system [81] and the developing hippocampus [82]. Thus, future studies could better assess the status of animal stress responses (e.g. corticosterone measurement) or avoid this confound altogether by breeding animals on site to eliminate shipping stress. An additional interpretive caveat regards the complex question of cause and effect relationships between gene expression and behavior, and the risk of implying that regional gene expression and functional networks are necessarily the drivers of behavior, rather than effects arising from the behaviors themselves. While the present studies demonstrate network-behavior associations, future studies could more mechanistically expand upon these findings by probing the causative roles of neuronal activation. For example, driving BNST neurons optogenetically could clarify if this nucleus plays developmentally distinct roles in modulating locomotor behaviors and functional networks. Lastly, these data imply an important role for stress sensitive systems in adolescence, despite the fact that stress was not specifically manipulated in these studies. Thus, future studies incorporating stress as an independent variable are warranted to more thoroughly characterize its relevance to DA-regulated behavioral networks.

\section{Conclusions}

Taken together, these data suggest that supra-additive behavioral D1/D2 interactions may be late maturing, and that functional and plasticity-related neural networks show age differences in their modulation by dopaminergic agonists. The BNST may function as an integrative switch, recruiting stress networks inhibitory to locomotor behaviors following D1/D2 stimulation in adolescents, but not adults, a hypothesis requiring further testing. IEG network analysis suggests that normal plasticity-related CGE is disrupted by D1/D2 stimulation in adolescence, with implications for the long-term effects of indirect agonists that are routinely administered clinically in this young population. In contrast, combined D1[Gq]/D2 stimulation produces greater behavioral activation than D1[Gs]/D2 in adults, which is associated with enhanced coordination of both activity- and plasticity-related gene expression in corticostriatal circuitry. Although novel, network methods using IEG data provide a high-resolution complement to analysis of traditional imaging techniques. Comparison of network development across species should allow greater translation of studies in rodents to humans, with potential for experimental psychopharmacology and validation of animal disease models.

\section{Supporting Information}

\section{S1 Fig. Example of Correlation Matrix.}

\section{S2 Fig. Example of Thresholded Correlation Matrix.}

(TIF) 
S3 Fig. Pseudoanatomical Regional Layout for Network Figures. Cingulate cortex (Cg1), prelimbic cortex (PrL), infralimbic cortex (IL), ventrolateral/orbital cortex (VLO), primary motor cortex (M1), secondary motor cortex (M2), primary sensory cortex (S1), caudal primary motor cortex (cM1), agranular insular cortex (AI), caudal agranular insular cortex (cAI), dorsomedial caudate putamen $(\mathrm{dmCPu})$, dorsolateral caudate putamen $(\mathrm{dlCPu})$, ventromedial caudate putamen $(\mathrm{vmCPu})$, ventrolateral caudate putamen $(\mathrm{vlCPu})$, nucleus accumbens core (NAcC), nucleus accumbens shell (NAcSh), CA1 of hippocampus (CA1), CA2 of hippocampus (CA2), CA3 of hippocampus (CA3), dentate gyrus (DG), medial septum (MS), lateral septum (LS), bed nucleus of the stria terminalis (BNST), paraventricular nucleus of the hypothalamus (PVN), basolateral amygdala (BLA), central nucleus of the amygdala (CeA), medial nucleus of the amygdala (MeA).

(TIF)

S4 Fig. Examples of stereotypy timecourses following injections of D1 or D2 agonists. While there are significant effects of time $(\mathrm{F}(5,38)=37.5, \mathrm{p}<0.001)$ and time $\mathrm{x}$ drug $(\mathrm{F}(10,78)$ $=3.2, \mathrm{p}=0.002)$, there is no significant effect of time $\mathrm{x}$ age $(\mathrm{F}(5,38)=0.578, \mathrm{p}=0.72)$. (JPG)

S1 File. This supplement provides a detailed description of the following methods. (I) behavioral testing procedures, (II) in situ hybridization conditions, (III) quantitative autoradiography analysis of immediate early gene expression, (IV) a step-by-step guide to the implementation of Coordinated Gene Expression (CGE) Analysis, the adaptation of functional network analysis to immediate early gene data, and $(\mathrm{V})$ a step-by-step guide to statistically comparing CGE networks.

(DOC)

S1 Table. Cfos regional gene expression. $\mathrm{N}=6-7 ;+\mathrm{p}<0.05$ vs. saline, $++\mathrm{p}<0.01,++$ $+\mathrm{p}<0.01,(+) \mathrm{p}<0.09$

S2 Table. Arc regional gene expression. $\mathrm{N}=6-7 ;+\mathrm{p}<0.05$ vs. saline, $++\mathrm{p}<0.01,+++\mathrm{p}<0.01$; ${ }^{* *} \mathrm{p}<0.01$ vs saline, additive doses of each agonist alone at same age, $\left({ }^{*}\right) \mathrm{p}<0.09$

\section{Acknowledgments}

This work was funded by NIH grant DA19138. Stipend support for JBD was provided in part from a PhRMA Foundation fellowship. A special thanks to the NIMH for generously providing SKF83822.

Supplies: A special thanks to the NIMH for providing SKF83822. The $c f o s$ plasmid was generously provided by Dr. Stanley Watson, University of Michigan, and the arc plasmid was kindly provided by Dr. Paul Worley, Johns Hopkins University.

\section{Author Contributions}

Conceived and designed the experiments: JBD FML. Performed the experiments: JBD. Analyzed the data: JBD FML. Contributed reagents/materials/analysis tools: FML. Wrote the paper: JBD FML. 


\section{References}

1. Johnston LD OMP, Bachman JG, Schulenberg JE (2005) Monitoring the Future National Survey Results on Drug Use, 1975-2005. Volume II: College Students and Adults Ages 19-45. NIH Publication No 06-5884: 278.

2. Lewis DA, Cruz D, Eggan S, Erickson S (2004) Postnatal development of prefrontal inhibitory circuits and the pathophysiology of cognitive dysfunction in schizophrenia. Ann N Y Acad Sci 1021: 64-76. PMID: 15251876

3. Giedd JN (2004) Structural magnetic resonance imaging of the adolescent brain. Ann N Y Acad Sci 1021: 77-85. PMID: 15251877

4. Fair DA, Cohen AL, Power JD, Dosenbach NU, Church JA, Miezin FM, et al. (2009) Functional brain networks develop from a "local to distributed" organization. PLoS Comput Biol 5: e1000381. doi: 10 1371/journal.pcbi.1000381 PMID: 19412534

5. Benes FM, Taylor JB, Cunningham MC (2000) Convergence and plasticity of monoaminergic systems in the medial prefrontal cortex during the postnatal period: implications for the development of psychopathology. Cereb Cortex 10: 1014-1027. PMID: 11007552

6. Wahlstrom D, White T, Luciana M (2010) Neurobehavioral evidence for changes in dopamine system activity during adolescence. Neurosci Biobehav Rev 34: 631-648. doi: 10.1016/j.neubiorev.2009.12. 007 PMID: 20026110

7. Rapoport JL, Buchsbaum MS, Weingartner H, Zahn TP, Ludlow C, Mikkelsen EJ (1980) Dextroamphetamine. Its cognitive and behavioral effects in normal and hyperactive boys and normal men. Arch Gen Psychiatry 37: 933-943. PMID: 7406657

8. Correll CU (2008) Assessing and maximizing the safety and tolerability of antipsychotics used in the treatment of children and adolescents. J Clin Psychiatry 69 Suppl 4: 26-36. PMID: 18533766

9. Spear LP (2000) The adolescent brain and age-related behavioral manifestations. Neurosci Biobehav Rev 24: 417-463. PMID: 10817843

10. Fuhrmann D, Knoll LJ, Blakemore SJ (2015) Adolescence as a Sensitive Period of Brain Development. Trends Cogn Sci.

11. Yuan M, Cross SJ, Loughlin SE, Leslie FM (2015) Nicotine and the adolescent brain. J Physiol 593: 3397-3412. doi: 10.1113/JP270492 PMID: 26018031

12. Laviola G, Wood RD, Kuhn C, Francis R, Spear LP (1995) Cocaine sensitization in periadolescent and adult rats. J Pharmacol Exp Ther 275: 345-357. PMID: 7562570

13. Bolanos CA, Glatt SJ, Jackson $D$ (1998) Subsensitivity to dopaminergic drugs in periadolescent rats: a behavioral and neurochemical analysis. Brain Res Dev Brain Res 111: 25-33. PMID: 9804875

14. McQuown SC, Dao JM, Belluzzi JD, Leslie FM (2009) Age-dependent effects of low-dose nicotine treatment on cocaine-induced behavioral plasticity in rats. Psychopharmacology (Berl) 207: 143-152.

15. Cao J, Lotfipour S, Loughlin SE, Leslie FM (2007) Adolescent maturation of cocaine-sensitive neural mechanisms. Neuropsychopharmacology 32: 2279-2289. PMID: 17299504

16. Caster JM, Kuhn CM (2009) Maturation of coordinated immediate early gene expression by cocaine during adolescence. Neuroscience 160: 13-31. doi: 10.1016/j.neuroscience.2009.01.001 PMID: 19245875

17. Neve KA, Seamans JK, Trantham-Davidson H (2004) Dopamine receptor signaling. J Recept Signal Transduct Res 24: 165-205. PMID: 15521361

18. Mahan LC, Burch RM, Monsma FJ Jr., Sibley DR (1990) Expression of striatal D1 dopamine receptors coupled to inositol phosphate production and $\mathrm{Ca} 2+$ mobilization in Xenopus oocytes. Proc Natl Acad Sci U S A 87: 2196-2200. PMID: 1690425

19. Rashid AJ, So CH, Kong MM, Furtak T, El-Ghundi M, Cheng R, et al. (2007) D1-D2 dopamine receptor heterooligomers with unique pharmacology are coupled to rapid activation of $\mathrm{Gq} / 11$ in the striatum. Proc Natl Acad Sci U S A 104: 654-659. PMID: 17194762

20. Andersen PH, Jansen JA (1990) Dopamine receptor agonists: selectivity and dopamine D1 receptor efficacy. Eur J Pharmacol 188: 335-347. PMID: 1973652

21. Andersen SL (2002) Changes in the second messenger cyclic AMP during development may underlie motoric symptoms in attention deficit/hyperactivity disorder (ADHD). Behav Brain Res 130: 197-201. PMID: 11864735

22. Brenhouse HC, Sonntag KC, Andersen SL (2008) Transient D1 dopamine receptor expression on prefrontal cortex projection neurons: relationship to enhanced motivational salience of drug cues in adolescence. J Neurosci 28: 2375-2382. doi: 10.1523/JNEUROSCI.5064-07.2008 PMID: 18322084 
23. Tarazi FI, Tomasini EC, Baldessarini RJ (1999) Postnatal development of dopamine D1-like receptors in rat cortical and striatolimbic brain regions: An autoradiographic study. Dev Neurosci 21: 43-49. PMID: 10077701

24. Teicher MH, Krenzel E, Thompson AP, Andersen SL (2003) Dopamine receptor pruning during the peripubertal period is not attenuated by NMDA receptor antagonism in rat. Neurosci Lett 339: 169171. PMID: 12614921

25. Frantz KJ, Van Hartesveldt C (1999) The locomotor effects of quinpirole in rats depend on age and gender. Pharmacol Biochem Behav 64: 821-826. PMID: 10593206

26. Chen YI, Choi JK, Xu H, Ren J, Andersen SL, Jenkins BG (2010) Pharmacologic neuroimaging of the ontogeny of dopamine receptor function. Dev Neurosci 32: 125-138. doi: 10.1159/000286215 PMID: 20523024

27. LaHoste GJ, Ruskin DN, Marshall JF (1996) Cerebrocortical Fos expression following dopaminergic stimulation: D1/D2 synergism and its breakdown. Brain Res 728: 97-104. PMID: 8864302

28. Svenningsson $P$, Fredholm BB, Bloch $B$, Le Moine $C(2000)$ Co-stimulation of $D(1) / D(5)$ and $D(2)$ dopamine receptors leads to an increase in c-fos messenger RNA in cholinergic interneurons and a redistribution of c-fos messenger RNA in striatal projection neurons. Neuroscience 98: 749-757. PMID: 10891618

29. Pollack A (2004) Coactivation of D1 and D2 dopamine receptors: in marriage, a case of his, hers, and theirs. Sci STKE 2004: pe50. PMID: 15494560

30. Moody CA, Spear LP (1992) Ontogenetic differences in the psychopharmacological responses to separate and combined stimulation of D1 and D2 dopamine receptors during the neonatal to weanling age period. Psychopharmacology (Berl) 106: 161-168.

31. Bowman BP, Blatt B, Kuhn CM (1997) Ontogeny of the behavioral response to dopamine agonists after chronic cocaine. Psychopharmacology (Berl) 129: 121-127.

32. O'Sullivan GJ, Roth BL, Kinsella A, Waddington JL (2004) SK\&F 83822 distinguishes adenylyl cyclase from phospholipase C-coupled dopamine D1-like receptors: behavioural topography. Eur J Pharmacol 486: 273-280. PMID: 14985049

33. Jin LQ, Goswami S, Cai G, Zhen X, Friedman E (2003) SKF83959 selectively regulates phosphatidylinositol-linked D1 dopamine receptors in rat brain. J Neurochem 85: 378-386. PMID: 12675914

34. Dao JM, McQuown SC, Loughlin SE, Belluzzi JD, Leslie FM (2011) Nicotine alters limbic function in adolescent rat by a 5-HT1A receptor mechanism. Neuropsychopharmacology 36: 1319-1331. doi: 10. 1038/npp.2011.8 PMID: 21412223

35. Tallarida RJ (2001) Drug synergism: its detection and applications. J Pharmacol Exp Ther 298: 865872. PMID: 11504778

36. Johnstone TB, Gu Z, Yoshimura RF, Villegier AS, Hogenkamp DJ, Whittemore ER, et al. (2011) Allosteric modulation of related ligand-gated ion channels synergistically induces long-term potentiation in the hippocampus and enhances cognition. J Pharmacol Exp Ther 336: 908-915. doi: 10.1124/jpet.110. 176255 PMID: 2115975

37. Guzowski JF, McNaughton BL, Barnes CA, Worley PF (1999) Environment-specific expression of the immediate-early gene Arc in hippocampal neuronal ensembles. Nat Neurosci 2: 1120-1124. PMID: 10570490

38. Cullinan WE, Herman JP, Battaglia DF, Akil H, Watson SJ (1995) Pattern and time course of immediate early gene expression in rat brain following acute stress. Neuroscience 64: 477-505. PMID: 7700534

39. Winzer-Serhan UH, Broide RS, Chen Y, Leslie FM (1999) Highly sensitive radioactive in situ hybridization using full length hydrolyzed riboprobes to detect alpha 2 adrenoceptor subtype mRNAs in adult and developing rat brain. Brain Res Brain Res Protoc 3: 229-241. PMID: 9974137

40. Gardner EL, Schiffer WK, Horan BA, Highfield D, Dewey SL, Brodie JD, et al. (2002) Gamma-vinyl GABA, an irreversible inhibitor of GABA transaminase, alters the acquisition and expression of cocaine-induced sensitization in male rats. Synapse 46: 240-250. PMID: 12373739

41. LaHoste GJ, Marshall JF (1993) The role of dopamine in the maintenance and breakdown of D1/D2 synergism. Brain Res 611: 108-116. PMID: 8518938

42. Schmider E, Ziegler M, Danay E, Beyer L, Bühner M (2015) Is it really robust? Methodology 6: 147151.

43. Rubinov M, Sporns $\mathrm{O}$ (2010) Complex network measures of brain connectivity: uses and interpretations. Neuroimage 52: 1059-1069. doi: 10.1016/j.neuroimage.2009.10.003 PMID: 19819337

44. Bullmore E, Sporns $\mathrm{O}$ (2009) Complex brain networks: graph theoretical analysis of structural and functional systems. Nat Rev Neurosci 10: 186-198. doi: 10.1038/nrn2575 PMID: 19190637 
45. Genovese CR, Lazar NA, Nichols $T$ (2002) Thresholding of statistical maps in functional neuroimaging using the false discovery rate. Neuroimage 15:870-878. PMID: 11906227

46. Zalesky A, Fornito A, Bullmore ET (2010) Network-based statistic: identifying differences in brain networks. Neuroimage 53: 1197-1207. doi: 10.1016/j.neuroimage.2010.06.041 PMID: 20600983

47. McElligott ZA, Winder DG (2009) Modulation of glutamatergic synaptic transmission in the bed nucleus of the stria terminalis. Prog Neuropsychopharmacol Biol Psychiatry 33: 1329-1335. doi: 10.1016/j. pnpbp.2009.05.022 PMID: 19524008

48. Georges F, Aston-Jones G (2002) Activation of ventral tegmental area cells by the bed nucleus of the stria terminalis: a novel excitatory amino acid input to midbrain dopamine neurons. J Neurosci 22 5173-5187. PMID: 12077212

49. Choi DC, Furay AR, Evanson NK, Ostrander MM, Ulrich-Lai YM, Herman JP (2007) Bed nucleus of the stria terminalis subregions differentially regulate hypothalamic-pituitary-adrenal axis activity: implications for the integration of limbic inputs. J Neurosci 27: 2025-2034. PMID: 17314298

50. Fox MD, Snyder AZ, Vincent JL, Corbetta M, Van Essen DC, Raichle ME (2005) The human brain is intrinsically organized into dynamic, anticorrelated functional networks. Proc Natl Acad Sci U S A 102: 9673-9678. PMID: 15976020

51. Stevens MC, Pearlson GD, Calhoun VD (2009) Changes in the interaction of resting-state neural networks from adolescence to adulthood. Hum Brain Mapp 30: 2356-2366. doi: 10.1002/hbm.20673 PMID: 19172655

52. Braun AR, Chase TN (1986) Obligatory D-1/D-2 receptor interaction in the generation of dopamine agonist related behaviors. Eur J Pharmacol 131: 301-306. PMID: 3493161

53. Delfs JM, Kelley AE (1990) The role of D1 and D2 dopamine receptors in oral stereotypy induced by dopaminergic stimulation of the ventrolateral striatum. Neuroscience 39: 59-67. PMID: 1982467

54. LaHoste GJ, Marshall JF (1992) Dopamine supersensitivity and D1/D2 synergism are unrelated to changes in striatal receptor density. Synapse 12: 14-26. PMID: 1357762

55. Mojica CY, Dao JM, Yuan M, Loughlin SE, Leslie FM (2014) Nicotine modulation of adolescent dopamine receptor signaling and hypothalamic peptide response. Neuropharmacology 77: 285-293. doi: 10.1016/j.neuropharm.2013.10.012 PMID: 24157491

56. Andersen SL, Thompson AT, Rutstein M, Hostetter JC, Teicher MH (2000) Dopamine receptor pruning in prefrontal cortex during the periadolescent period in rats. Synapse 37: 167-169. PMID: 10881038

57. Tseng KY, O'Donnell $P$ (2007) Dopamine modulation of prefrontal cortical interneurons changes during adolescence. Cereb Cortex 17: 1235-1240. PMID: 16818475

58. Macey DJ, Smith HR, Nader MA, Porrino LJ (2003) Chronic cocaine self-administration upregulates the norepinephrine transporter and alters functional activity in the bed nucleus of the stria terminalis of the rhesus monkey. J Neurosci 23: 12-16. PMID: 12514195

59. Xu HY, Liu YJ, Xu MY, Zhang YH, Zhang JX, Wu YJ (2012) Inactivation of the bed nucleus of the stria terminalis suppresses the innate fear responses of rats induced by the odor of cat urine. Neuroscience 221: 21-27. doi: 10.1016/j.neuroscience.2012.06.056 PMID: 22766237

60. Daniel SE, Rainnie DG (2015) Stress Modulation of Opposing Circuits in the Bed Nucleus of the Stria Terminalis. Neuropsychopharmacology.

61. Horwitz B, McIntosh AR, Haxby JV, Grady CL (1995) Network analysis of brain cognitive function using metabolic and blood flow data. Behav Brain Res 66: 187-193. PMID: 7755889

62. Sporns $\mathrm{O}$ (2002) Network Analysis, complexity, and brain function. Complexity 8: 56-60.

63. Achard S, Bullmore E (2007) Efficiency and cost of economical brain functional networks. PLoS Comput Biol 3: e17. PMID: 17274684

64. Stam CJ (2004) Functional connectivity patterns of human magnetoencephalographic recordings: a 'small-world' network? Neurosci Lett 355: 25-28. PMID: 14729226

65. Sadaghiani S, Scheeringa R, Lehongre K, Morillon B, Giraud AL, Kleinschmidt A (2010) Intrinsic connectivity networks, alpha oscillations, and tonic alertness: a simultaneous electroencephalography/ functional magnetic resonance imaging study. J Neurosci 30: 10243-10250. doi: 10.1523/ JNEUROSCI.1004-10.2010 PMID: 20668207

66. Horwitz B, Duara R, Rapoport SI (1984) Intercorrelations of glucose metabolic rates between brain regions: application to healthy males in a state of reduced sensory input. J Cereb Blood Flow Metab 4: 484-499. PMID: 6501442

67. Schwarz AJ, Gozzi A, Bifone A (2008) Community structure and modularity in networks of correlated brain activity. Magn Reson Imaging 26: 914-920. doi: 10.1016/j.mri.2008.01.048 PMID: 18479871

68. Sagar SM, Sharp FR, Curran T (1988) Expression of c-fos protein in brain: metabolic mapping at the cellular level. Science 240: 1328-1331. PMID: 3131879 
69. Dragunow M, Faull R (1989) The use of c-fos as a metabolic marker in neuronal pathway tracing. J Neurosci Methods 29: 261-265. PMID: 2507830

70. Lyford GL, Yamagata K, Kaufmann WE, Barnes CA, Sanders LK, Copeland NG, et al. (1995) Arc, a growth factor and activity-regulated gene, encodes a novel cytoskeleton-associated protein that is enriched in neuronal dendrites. Neuron 14: 433-445. PMID: 7857651

71. Guzowski JF, Lyford GL, Stevenson GD, Houston FP, McGaugh JL, Worley PF, et al. (2000) Inhibition of activity-dependent arc protein expression in the rat hippocampus impairs the maintenance of longterm potentiation and the consolidation of long-term memory. J Neurosci 20: 3993-4001. PMID: 10818134

72. Horwitz B, Duara R, Rapoport SI (1986) Age differences in intercorrelations between regional cerebral metabolic rates for glucose. Ann Neurol 19: 60-67. PMID: 3484930

73. Fair DA, Dosenbach NU, Church JA, Cohen AL, Brahmbhatt S, Miezin FM, et al. (2007) Development of distinct control networks through segregation and integration. Proc Natl Acad Sci U S A 104: 1350713512. PMID: 17679691

74. Cunningham MG, Bhattacharyya S, Benes FM (2002) Amygdalo-cortical sprouting continues into early adulthood: implications for the development of normal and abnormal function during adolescence. $J$ Comp Neurol 453: 116-130. PMID: 12373778

75. Robinson TE, Gorny G, Mitton E, Kolb B (2001) Cocaine self-administration alters the morphology of dendrites and dendritic spines in the nucleus accumbens and neocortex. Synapse 39:257-266. PMID: 11169774

76. Frantz KJ, O'Dell LE, Parsons LH (2007) Behavioral and neurochemical responses to cocaine in periadolescent and adult rats. Neuropsychopharmacology 32: 625-637. PMID: 16794567

77. Mathews IZ, Brudzynski SM, McCormick CM (2011) Heightened locomotor-activating effects of amphetamine administered into the nucleus accumbens in adolescent rats. Int J Dev Neurosci 29: 501-507. doi: 10.1016/j.ijdevneu.2011.05.003 PMID: 21616135

78. Robinson TE, Berridge KC (2003) Addiction. Annu Rev Psychol 54: 25-53. PMID: 12185211

79. Hasbi A, Fan T, Alijaniaram M, Nguyen T, Perreault ML, O'Dowd BF, et al. (2009) Calcium signaling cascade links dopamine D1-D2 receptor heteromer to striatal BDNF production and neuronal growth. Proc Natl Acad Sci U S A 106: 21377-21382. doi: 10.1073/pnas.0903676106 PMID: 19948956

80. Bahi A, Boyer F, Chandrasekar V, Dreyer JL (2008) Role of accumbens BDNF and TrkB in cocaineinduced psychomotor sensitization, conditioned-place preference, and reinstatement in rats. Psychopharmacology (Berl) 199: 169-182.

81. Rodrigues AJ, Leao P, Carvalho M, Almeida OF, Sousa N (2011) Potential programming of dopaminergic circuits by early life stress. Psychopharmacology (Berl) 214: 107-120.

82. Wei L, Hao J, Lacher RK, Abbott T, Chung L, Colangelo CM, et al. (2015) Early-Life Stress Perturbs Key Cellular Programs in the Developing Mouse Hippocampus. Dev Neurosci. 